\title{
Desidratação e composição química do feno de Leucena (Leucena leucocephala) e Gliricidia (Gliricidia sepium)
}

\author{
Dehydration and chemical composition of Leucena ("Leucena leucocephala") and \\ Gliricidia ("Gliricidia sepium”)
}

\author{
BAYÃO, Geraldo Fábio Viana ${ }^{1 *}$; EDVAN, Ricardo Loiola ${ }^{1}$; CARNEIRO, Maria \\ Socorro de Souza ${ }^{2}$; FREITAS, Natylane Eufransino ${ }^{1}$; PEREIRA, Elzânia Sales ${ }^{2}$; \\ PACHECO,Weverton Filgueira ${ }^{2}$; BEZERRA, Leilson Rocha ${ }^{1}$; ARAÚJO, Marcos \\ Jácome de ${ }^{1}$
}

\footnotetext{
${ }^{1}$ Universidade Federal do Piauí, Programa de Pós-Graduação em Zootecnia, Bom Jesus, Piauí, Brasil.

${ }^{2}$ Universidade Federal do Ceará, Departamento de Zootecnia, Campus do Pici, Fortaleza, Ceará, Brasil.

*Endereço para correspondência: gfbayao@gmail.com
}

\section{RESUMO}

Objetivou-se avaliar a composição química e tempo para atingir o ponto de fenação da Leucena (Leucena leucocephala) e Gliricidia (Gliricidia sepium). Foram coletadas amostras nos tempos $0,2,4,6,8,10,12,14$, e 16 horas de secagem para obtenção da curva de desidratação para cada espécie de forragem. O delineamento adotado foi o inteiramente casualizado com nove tratamentos ( 9 tempos de desidratação $\mathrm{x}$ três repetições). Os dados referentes às características morfológicas da espécie foram submetidos à análise estatística de variância e as médias foram comparadas pelo teste de Tukey a $1 \%$ de probabilidade. Para a curva de desidratação em função do tempo, os dados foram submetidos à análise de regressão. A relação folha:caule foi maior para a Gliricidia no tempo 16 horas de desidratação $(\mathrm{P}<0,05)$. As taxas de desidratação da amostra composta, vagem, colmo e folha composta da Gliricidia e Leucena apresentaram efeito linear crescente $(\mathrm{P}<0,05)$ com a Leucena mais eficiente na desidratação. Os teores de matéria seca da Gliricidia e Leucena foram, respectivamente, de $91,24 \%$ e $91,32 \%$, enquanto os teores de proteína bruta foram de $18,64 \%$ e $17,7 \%$. Os teores de fibra em detergente neutro corrigida para cinzas e proteína foram de $49,86 \%$ e $49,07 \%$, e os teores de proteína insolúvel em detergente neutro foram de $1,01 \%$ e $1,77 \%$. O tempo para atingir o ponto de feno da Leucena e da Gliricidia foi de 16 horas. A composição nutricional dos fenos de Leucena e Gliricidia apresentaram-se satisfatórios para serem fornecidos na alimentação de animais ruminantes.

Palavras-chave: alimentos alternativos, semiárido, valor nutritivo

\section{SUMMARY}

The objective was to evaluate the chemical composition and time to reach the point of hay of Leucena (Leucena leucocephala) and Gliricidia (Gliricidia sepium). Samples were collected in time $0,2,4,6,8,10,12,14$, and 16 hours of drying to obtain dehydration curve for each species of forage. The design was completely randomized with nine treatments (9 times of dehydration $\mathrm{x}$ three replicates). Data for morphological characteristics of the species were subjected to statistical analysis of variance, and means were compared by Tukey test at $1 \%$ probability. For dehydration curve as a function of time, the data were subjected to regression analysis. The leaf:stem ratio was higher for Gliricidia in time and 16 hours of dehydration $(\mathrm{P}<0.05)$. The rates dehydration of Composed samples of pod, stem and leaf of Gliricidia and Leucena showed a linear increase $(\mathrm{P}<0.05)$ and the Leucena dehydration was most efficient. The dry matter content of Gliricidia and Leucena showed, respectively, $91.24 \%$ and $91.32 \%$ content, while the crude protein content 
was $18.64 \%$ and $17.7 \%$. The fiber content neutral detergent corrected for ash and protein content was the $49.86 \%$ and 49.07 , the neutral detergent insoluble protein content was $1.01 \%$ and $1.77 \%$. The time to reach the point of Leucena and Gliricidia hay was 16 hours. The nutritional composition of hay Leucena and Gliricidia were satisfactory to be provided in the feeding of ruminant animals.

Keyworks: alternative foods, nutritive value, semiarid

\section{INTRODUÇÃO}

A oscilação na produção de alimentos ao longo do ano assim como sua baixa qualidade são um problema no semiárido brasileiro. Mesmo as forrageiras mais adaptadas sofrem com os longos períodos de estiagem em função dos recorrentes desequilíbrios ambientais, prejudicando a sustentabilidade do sistema de produção animal.

Uma das formas de contornar tal dificuldade é a suplementação proteica por meio de concentrados. Porém, devido aos altos custos, esta alternativa torna-se antieconômica para muitos produtores inviabilizando sua utilização. Uma possibilidade viável é a utilização de feno de leguminosas como suplemento proteico a ser oferecido aos animais. A fenação de leguminosas constitui-se como uma possibilidade de conservação das forragens que podem ser utilizadas como suplemento ou alimento volumoso (PADUA et al, 2006), minimizando o problema de estacionalidade produtiva de forragens ao longo do ano.

A Leucena (Leucena leucocephala) é uma espécie adaptada do semiárido, com boa capacidade de rebrota, boa produtividade e com boa aceitação pelos animais ruminantes (CÂMARA et al., 2015). A Gliricidia (Gliricidia sepium) é resistente a seca, com boa capacidade de produzir biomassa em condições de baixa disponibilidade hídrica (MARIN, et al., 2007).

Estas leguminosas apresentam-se como alternativas em potencial para a produção de fenos a serem fornecidos em dietas para animais ruminantes do semiárido, já que apresentam em torno de 18 a $30 \%$ de proteína bruta, são adaptados a solos pobres e tem considerável produtividade (EDWARDS et al., 2012). No entanto, altas temperaturas ambientais proporcionam aumento da lignificação (VAN SOEST, 1994) e aumento do metabolismo da planta com consequente formação de tecidos estruturais e diminuição de metabólitos do conteúdo celular (PACIULLO et al, 2001). Desta forma, o corte em idade adequada da forrageira e sua fenação irá proporcionar $\mathrm{o}$ fornecimento de um alimento em quantidade e qualidade mais homogênea, resultando em maior produtividade animal.

Sabendo-se que a desidratação ajuda na conservação temporal da forrageira e o conhecimento do tempo do ponto de fenação evita que o feno fique acima ou abaixo do teor ideal de matéria seca, contribuindo para a maximização da qualidade e para a minimização das perdas no campo, objetivou-se com este trabalho avaliar a composição química do feno de Leucena (Leucena leucocephala) e Gliricidia (Gliricidia sepium), assim como determinar o tempo para atingir o ponto de fenação.

\section{MATERIAL E MÉTODOS}

O experimento foi desenvolvido no Setor de Forragicultura do Departamento de Zootecnia da Universidade Federal do Ceará - DZ/UFC, em Fortaleza, CE, situada à latitude $3^{\circ} 43^{\prime} 02^{\prime \prime} \mathrm{S}$ e longitude 
38 32'35" W no período de março a novembro de 2013.

As forrageiras utilizadas para produção do feno foram a Leucena (Leucena leucocephala) e Gliricidia (Gliricidia sepium) que constituíram-se de árvores com quatro anos de idade, locadas no Centro de Ciências Agrárias da UFC. O solo foi identificado como Podzólico Vermelho-Amarelo com as seguintes características químicas: $9 \mathrm{mg} \mathrm{\textrm {dm } ^ { - 3 }}$ de $\mathrm{P}$; $70 \mathrm{mg} \mathrm{dm}^{-3}$ de K; 3,5 $\mathrm{cmol} \mathrm{dm}^{-3}$ de $\mathrm{Ca}+$ $\mathrm{Mg} ; 0 \mathrm{cmol} \mathrm{dm}^{-3}$ de Al; $1,9 \mathrm{cmol} \mathrm{dm}^{-3}$ de $\mathrm{Ca} ; 1,6 \mathrm{cmol} \mathrm{dm}^{-3}$ de $\mathrm{Mg} ; 8 \mathrm{cmol} \mathrm{dm}^{-3}$ de $\mathrm{Na}$; e $\mathrm{pH}$ em $\mathrm{H}_{2} \mathrm{O}$ de 6,1 .

Para estimar a relação folha:caule, os cortes da forrageira foram realizados às 7 horas através de tesoura de poda e serrote de jardim. Em seguida, todo o material foi recolhido separando-se as folhas e ramos. Em parte do material coletado, foi realizado a separação manual das folhas e caule, não observando-se a presença de inflorescência, sendo coletadas três amostras da massa de forragem de cada espécie de forma representativa, sendo submetidos posteriormente à présecagem (65\%/72 horas) e determinação da relação folha:caule.

Para a produção de feno, a forrageira foi colhida, identificada as partes da planta, assim como a composta e processado em máquina estacionária ensiladeira modelo JF 50 MAXXIUM. Posteriormente, a massa de forragem foi colocada em lona plástica ao sol para secagem. Durante esta fase, o material foi revolvido a cada duas horas para garantir a uniformização do volumoso e permitir maior aeração para acelerar o processo de desidratação, visando atingir a umidade em torno de $10 \%$ para evitar a proliferação de microrganismos indesejados que possam resultar em alteração da composição química do feno.

Durante o processo de secagem para obtenção do feno, foram coletadas amostras de parte das plantas, assim como de sua composta, nos tempos 0,2 , $4,6,8,10,12,14$, e 16 horas de secagem para obtenção da curva de desidratação para cada espécie.

Os fenos de Leucena e Gliricidia foram analisados quimicamente quanto aos teores de matéria seca (MS), matéria orgânica (MO), proteína bruta (PB), extrato etéreo $(\mathrm{EE})$, proteína insolúvel em detergente ácido (PIDA) e proteína insolúvel em detergente neutro (PIDN), conforme recomendações de Detmann et al. (2012). Os teores de fibra em detergente neutro foram obtidos segundo Mertens (2002) e as correções da mesma para cinzas e proteína foram realizadas segundo Mertens (2002) e Licitra et al. (1996), respectivamente.

$\mathrm{O}$ delineamento adotado foi $\mathrm{o}$ inteiramente casualizado com nove tratamentos (tempos de desidratação) e três repetições. Os dados referentes às características morfológicas da espécie foram submetidos à análise estatística de variância, e as médias foram comparadas pelo teste de Tukey a $1 \%$ de probabilidade. Já para a curva de desidratação em função do tempo, os dados foram submetidos à análise de regressão, usando o pacote estatístico Sisvar 5.3 ao nível de $5 \%$ de probabilidade (FERREIRA, 2010).

\section{RESULTADOS E DISCUSSÃO}

A relação folha:caule no tempo zero das forrageiras Leucena e Gliricidia não apresentaram diferença $(\mathrm{P}>0,01)$, assim como no tempo 16 horas de desidratação (Figura 1). Já quando compara-se o tempo 0 horas com o tempo 16 horas, o feno de Gliricidia com 16 horas apresentou maior relação $(\mathrm{P}<0,01)$ folha:caule em relação ao tempo 0 (Figura 1). 


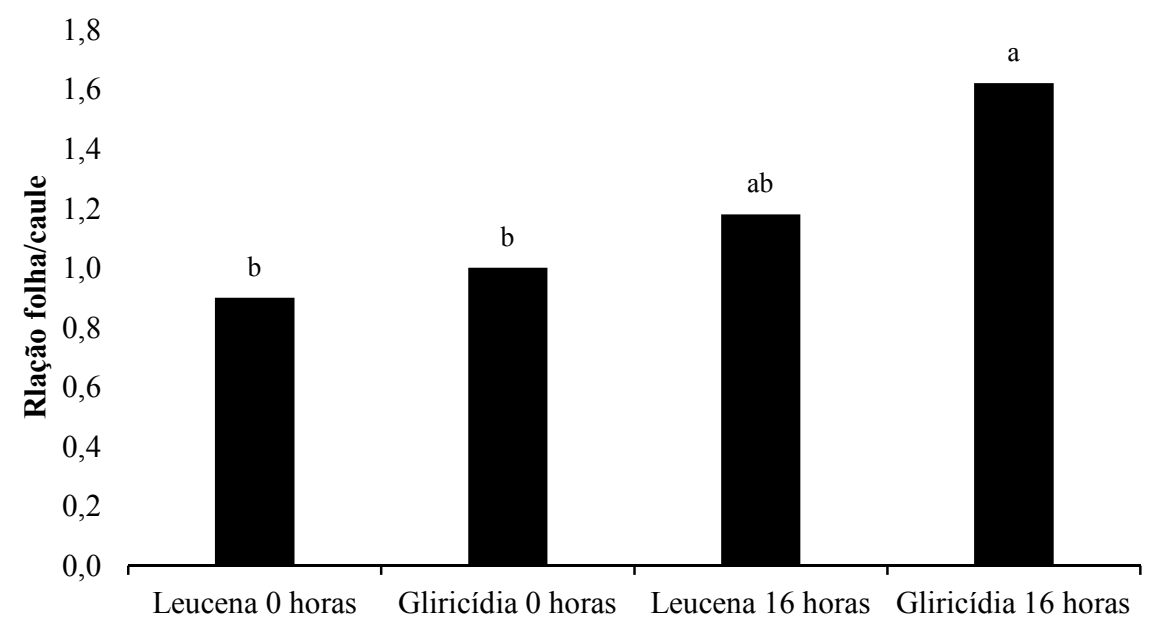

Figura 1. Relação folha:caule no tempo 0 e 16 horas para Leucena e Gliricidia. Coeficiente de variação $=14,3 \%$

Esperava-se que houvesse diminuição da relação folha:caule durante $o$ processo de desidratação. No entanto, apesar da perda de água no processo de desidratação tanto nas folhas quanto no caule, como esperado, estas perdas após as 16 horas de desidratação foram suficientes para diminuir o peso do caule de tal forma que a relação folha:caule aumentasse (Figura 1). Provavelmente, o caule apresentava-se com grande quantidade de umidade $o$ que ocasionou a maior perda de água em relação a folha, ocasionando $o$ aumento desta relação.

A relação folha:caule é uma variável importante para o processo de desidratação e do valor nutritivo do feno, pois quanto maior a quantidade de folhas no procedimento de fenação, há um tendência de melhoria da composição química e favorecimento no processo de desidratação (PINHO, et al., 2013). Da mesma forma, Van Soest (1994) afirma que quanto maior a relação folha:caule, maior será o valor nutritivo da forragem, uma vez que os nutrientes estão inseridos na MS da forragem e melhores serão os reflexos em produtividade animal.
De acordo com a equação de regressão para a Leucena, que leva em conta o teor de MS em função do período de desidratação, para a folha verificou-se que no tempo 16 horas o teor de MS foi de $87,1 \%$ e para o caule o teor de matéria seca foi de 59,4\% (Figura 2), enquanto o teor de MS para a folha e caule do feno de Gliricidia no tempo 16 horas foi de $83,2 \%$ e $68,4 \%$ respectivamente (Figura 3). O teor de matéria seca recomendado para fenos é de $85 \%$ a $90 \%$ (NERES \& AMES, 2015) sendo as folhas de Leucena apresentaram-se dentro desta recomendação.

As folhas, por apresentar uma densidade de estômatos maior que o caule, tendem a ter uma secagem mais rápida, já que a densidade dos estômatos são um dos fatores relacionados com a taxa de secagem, assim como comprimento do caule, espessura da cutícula e relação folha:caule (McDONALD \& CLARK, 1987). O caule, tanto da Leucena quanto da Gliricidia, apresentaram mais dificuldade de desidratação (Figura 2 e 3) em relação a folha devido à dificuldade de perda de água daquele por ser um tecido de sustentação. Esta menor velocidade de desidratação do 
Rev. Bras. Saúde Prod. Anim., Salvador, v.17, n.3, p.365-373 jul./set., $2016 \quad \underline{\text { http://www.rbspa.ufba.br }}$ ISSN 15199940

caule em relação as folhas permite a continuidade da dinâmica celular das plantas e microrganismos por um período mais elevado (PINHO et al., 2013). Além disso, deve-se considerar

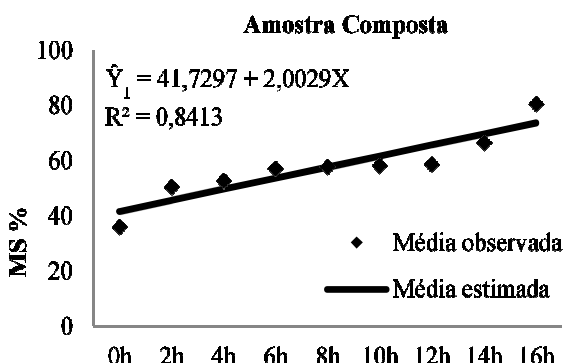

Perfodo de desidrataçăo

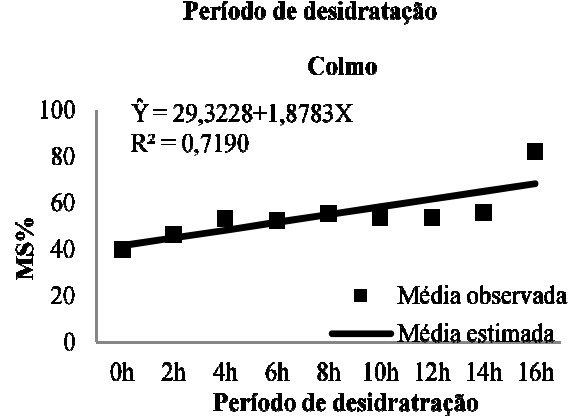

que a transferência de água do caule para as folhas é um fator que influencia a velocidade de secagem, demonstrando a maior capacidade de desidratação das folhas.

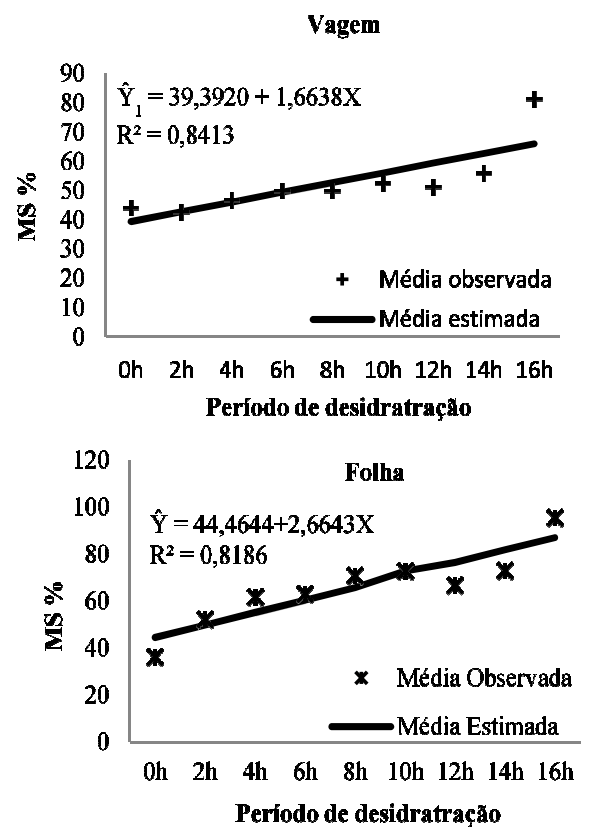

Figura 2. Porcentagem de matéria seca do feno de Leucena em relação aos tempos de desidratação

Comparando a folha do feno de Gliricidia (Figura 3) com a folha do feno de Leucena (Figura 2) e as equações de regressão, verifica-se pela inclinação da reta que a folha da Leucena apresentou-se mais eficiente na perda de água, com teor de MS superior, demonstrando que as folhas da Leucena atingem o ponto de fenação mais rápido. Apesar das mesmas condições climáticas, as diferenças entre as espécies da forrageira foi fator causador da diferença no tempo de desidratação.

A análise da amostra composta é importante, pois como esta reuni todos os componentes da planta, é mais representativa das condições de campo. Assim, ao compararmos as equações de regressão da amostra composta das duas leguminosas, verifica-se que a velocidade de desidratação da Leucena é maior que da Gliricidia, obtendo-se, consequentemente, uma inclinação da reta maior (Figura 2 e 3). Conforme Zanine \& Diniz (2006), quanto mais rápido a leguminosa se desidrata, menores serão as chances de deterioração da mesma, favorecendo assim a qualidade nutritiva do feno. Por outro lado, ao analisar a equação de regressão da composta das duas forrageiras, observa-se teor de MS de $73,8 \%$ e $73,6 \%$ no período de 16 horas (Figura 2 e 3) para o feno de Leucena e Gliricidia, apresentando, portanto, teores semelhantes. 
Rev. Bras. Saúde Prod. Anim., Salvador, v.17, n.3, p.365-373 jul./set., $2016 \quad \underline{\text { http://www.rbspa.ufba.br }}$ ISSN 15199940

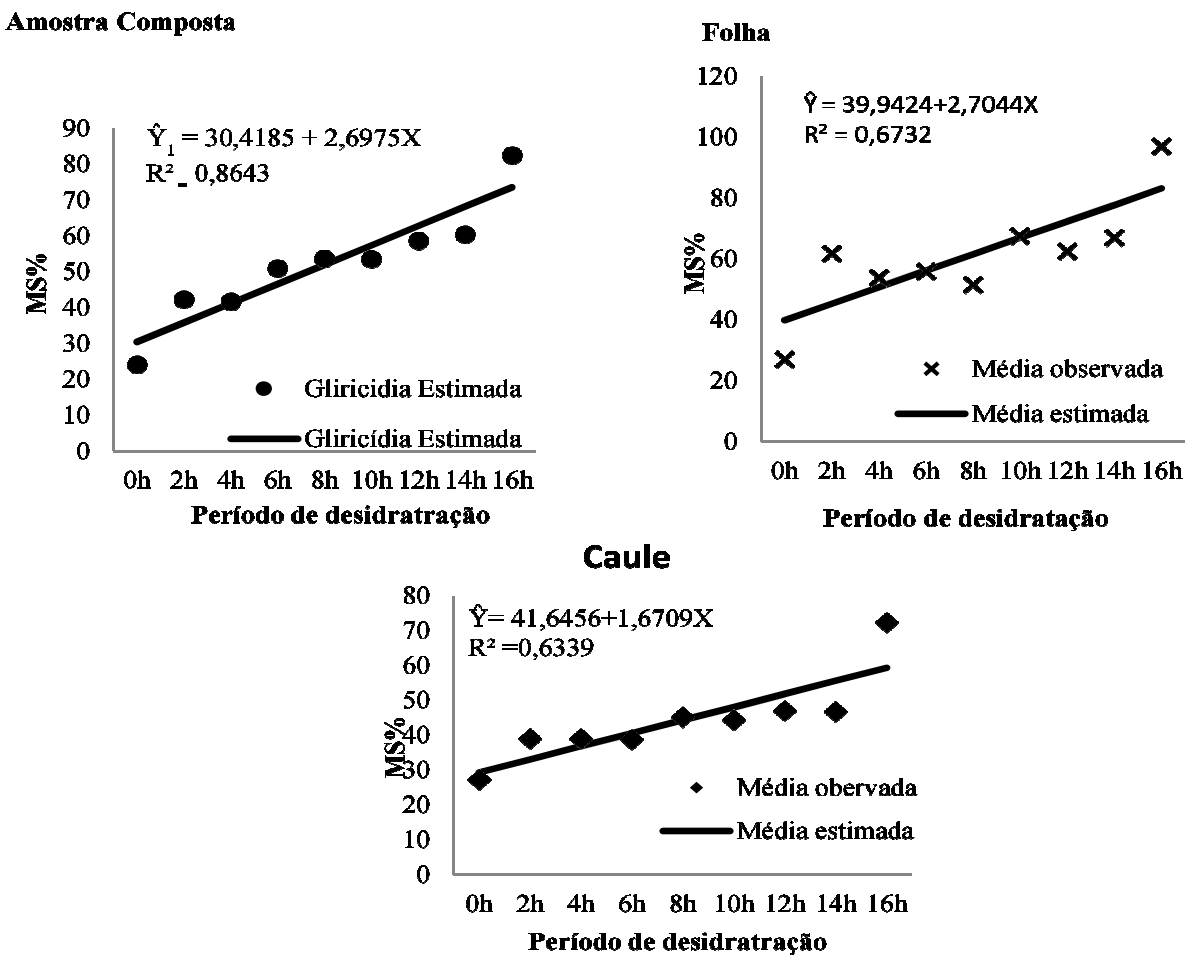

Figura 3. Porcentagem de matéria seca do feno de Gliricidia em relação aos tempos de desidratação

Ao verificarmos a composição química do feno das duas forrageiras (Tabela 1), observa-se teor de MS superiores a 90\%, demonstrando que a fenação foi eficiente, uma vez que o ponto de feno é quando a forrageira apresentar o teor de umidade entre $10 \%$ e $18 \%$ (EVANGELISTA \& LIMA, 2013). Alterações durante a secagem, recolhimento e armazenamento influenciam de forma significativa na composição química, ingestão e digestibilidade da forragem (JOBIM et al., 2007) e por isso, um maior teor de MS na fenação é fundamental para evitar o desenvolvimento de microrganismos indesejáveis que podem degradar a forragem.

Tabela 1. Composição química do feno de Leucena e a Gliricidia

\begin{tabular}{lcc}
\hline Item & Gliricidia & Leucena \\
\hline Matéria seca & 91,24 & 91,32 \\
Matéria orgânica $^{1}$ & 93,52 & 94,35 \\
Proteína Bruta $^{1}$ & 18,64 & 17,70 \\
Extrato etéreo $^{1}$ & 5,55 & 4,15 \\
Carboidratos não fibrosos $^{1,2}$ & 19,47 & 23,43 \\
Fibra em detergente neutro cp $^{1}$ & 49,86 & 49,07 \\
Proteína insolúvel em detergente neutro $^{3}$ & 1,01 & 1,77 \\
Proteína insolúvel em detergente ácido $^{3}$ & 0,67 & 1,41 \\
\hline
\end{tabular}

${ }^{\mathrm{T}} \mathrm{MS} ;{ }^{2} \mathrm{CNF}=100-\mathrm{PB}-\mathrm{EE}-\mathrm{MM}-\mathrm{FDN}$, onde $\mathrm{PB}=$ proteína bruta, $\mathrm{EE}=$ extrato etéreo, $\mathrm{MM}=$ matéria mineral e FDN $=$ Fibra em detergente neutro; ${ }^{3} \% \mathrm{~PB} ; \mathrm{cp}=$ corrigida para cinzas e proteínas 
Outro fator que pode ocasionar perdas devido a umidade nos fenos é devido a perdas por respiração celular e fermentação (EVANGELISTA \& LIMA, 2013), proporcionando diminuição do valor nutritivo do volumoso. Além disto, em função da alta umidade e fermentação, pode ocasionar aumento de temperatura dos fenos e consequentemente mudança na qualidade do produto final (COBLENTZ et al., 1996). Desta forma, os teores de MS dos fenos de Leucena e Gliricidia apresentaram-se adequados para evitar possíveis perdas por umidade.

$\mathrm{O}$ teor de $\mathrm{PB}$ do feno de Gliricidia (Tabela 1) apresentou teores acima dos $13,9 \%$ observados por Pacheco et al. (2013), assim como o feno de Leucena (Tabela 1) que apresentou teores acima dos $11,7 \%$ de PB constatados por Wanderley et al. (2012). Estes teores apresentaram-se acima dos 7\% recomendados por Sampaio et al. (2009) na alimentação de animais ruminantes, cujo teor mínimo é necessário para garantir uma fermentação ruminal adequada. Fenos de leguminosas são consideravelmente superiores aos de gramíneas em termos de proteína bruta (EVANGELISTA \& LIMA, 2013), o que pode reduzir a suplementação concentrada em proteína. Este alto teor de $\mathrm{PB}$ remete à qualidade do feno das leguminosas sendo uma alternativa interessante para o fornecimento aos animais, principalmente na época de escassez de alimentação volumosa, podendo ser utilizados como bancos de proteína na formulação de rações para animais ruminantes.

Associado ao teor de MS e PB, os teores de FDNcp das leguminosas apresentaram-se com um teor que favorece $\mathrm{o}$ valor nutricional em comparação com a maioria das gramíneas tropicais. O teor de FDNcp das leguminosas normalmente é duas vezes menor que das gramíneas tropicais (SANDERSON \& WEDIN, 1989), o que deve ser levado em consideração na sua utilização para balanceamento de dietas. Assim, o valor nutritivo das forrageiras Leucena $\mathrm{e}$ Gliricidia apresenta-se como uma alternativa viável para o fornecimento de animais ruminantes.

Geralmente as leguminosas apresentam teores de extrato etéreo maiores que de gramíneas. O teor de extrato etéreo para a grande maioria das gramíneas é no máximo de 4\% (CHURCH, 1988), enquanto os fenos de Gliricidia e Leucena apresentaram teores de 5,55\% e 4,15\% (Tabela 1). Apesar deste maior teor de EE, o mesmo está abaixo do preconizado por Lana et al. (2007), em que aconselha teores abaixo de $5-7 \%$ de EE na base da MS em dietas para ruminantes.

As estimativas para PIDN e PIDA para as duas leguminosas apresentaram baixos teores (menor que 2\%) em relação a proteína bruta (Tabela 1), o que é desejável, uma vez que estes valores estão relacionados com os contaminantes que causam a superestimação dos teores de FDN e FDA nos alimentos (DETMANN et al., 2012), comprometendo, portanto, o balanceamento das dietas. Dessa forma, espera-se que tenha menores valores de PIDN e PIDA, uma vez que sua presença relaciona-se com a fração proteica indisponível aos microrganismos ruminais, podendo causar diminuição da produtividade dos animais.

Dessa forma, o tempo para atingir o ponto de feno da Leucena e da Gliricidia foi de 16 horas. A composição nutricional dos fenos de Leucena e Gliricidia apresentaram-se satisfatórios para serem fornecidos na alimentação de animais ruminantes. 
Rev. Bras. Saúde Prod. Anim., Salvador, v.17, n.3, p.365-373 jul./set., $2016 \quad$ http://www.rbspa.ufba.br ISSN 15199940

\section{REFERÊNCIAS}

CÂMARA, C.S.; ALVES, A.A.; FILHO, M.A.M., GARCEZ, B.S.; AZEVÊDO, D.M.M.R. Dietas contendo fenos de leucena ou estilosantes para cabras Anglo-Nubianas de tipo misto em lactação. Revista Ciência Agronômica, v.46, n.2, p.443-450, 2015.

COBLENTZ, W.K.; FRITZ, J.O.; BOLSEN, K.K.;COCHAN, R.C. Quality changes in alfalfa hay duringstorage in bales. Journal of Dairy Science, v.79, n.5, p.873-885, 1996.

CHURCH, D.C. El Ruminante: Fisiologia digestive y nutrition. 3.ed. Oxford: Oxford Press, 1988. 641p.

DETMANN, E.; SOUZA, M.A.; VALADARES FILHO, S.C. S.C.; QUEIROZ, A. C.; BERCHIELLI, T. T.; SALIBA, E. O. S.; CABRAL, L. S.; PINA, D. S.; LADEIRA, M. M., AZEVEDO, J. A. G. Métodos para análise de alimentos. 1.ed.Visconde do Rio Branco, MG: Suprema, 2012. 214p.

EDWARDS, A.; MLAMBO, V.; LALLO, C.H.O.; GARCIA, G.W. Yield, chemical composition and In Vitro Ruminal Fermentation of the Leaves of Leucaena Leucocephala, Gliricidia Sepium and Trichanthera Gigantea as Influenced by Harvesting Frequency. Journal of Animal Science Advances, v.2, suppl. 3.2, p.321-331, 2012.

EVANGELISTA, A.R.; LIMA, J.A. Produção de feno. Informe

Agropecuário, v. 34, n.277, p.43-52, 2013.
FERREIRA, D. F. SISVAR - Sistema de análise de variância. Versão 5.3. Lavras,MG: UFLA, 2010.

JOBIM, C.C.; NUSSIO, L.G.; REIS, R.A.; SCHMIDT, P. Avanços metodológicos na avaliação da qualidade da forragem conservada.

Revista Brasileira de Zootecnia, v.36, p.101-119, 2007.

LANA, R.P.; CAMARDELLI, M.M.L.; RODRIGUES, M.T.; EIFERT, E.C.; OLIVEIRA, M.V.M.; STRADIOTTI JÚNIOR, D.; OLIVEIRA, J.S. Óleo de soja e própolis na alimentação de cabras leiteiras: consumo de matéria seca e de nutrientes e parâmetros de fermentação ruminal. Revista Brasileira de

Zootecnia, v.36, n.1, p.191-197, 2007

LICITRA, G.; HERNANDEZ, T.M.; VAN SOEST, P.J. Standardization of procedures for nitrogen fractionation of ruminant feeds. Animal Feed Science Technology, n.57, p.347-358, 1996.

MARIN, A.M.P.; MENEZES, R.S.C.; SALCEDO, I.H. Produtividade de milho solteiro ou em aléias de Gliricídia adubado com duas fontes orgânicas.

Pesquisa Agropecuária Brasileira, v.42, n.5, p.669-677, 2007.

McDONALD, A.D., CLARK, E.A. Water and quality loss during field drying of hay. Advances in Agronomy, v.41, p.407-437, 1987.

MERTENS, D.R. Gravimetric determination of amylase-treated neutral detergent fiber in feeds with refluxing in beakers or crucibles: collaborative study. Journalof AOAC International, v.85, n.6 p.1217-1240, 2002. 
Rev. Bras. Saúde Prod. Anim., Salvador, v.17, n.3, p.365-373 jul./set., $2016 \quad \underline{\text { http://www.rbspa.ufba.br }}$ ISSN 15199940

NERES, M.A.; AMES, J.P. Novos aspectos relacionados à produção de feno no Brasil. Scientia Agraria Paranaensis, v.14, n.1, p.10-17, 2015.

PACHECO, W.F.; CARNEIRO, M.S.S.; EDVAN, R.L.; ARRUDA; P.C.L.; CARMO, A.B.R. Valor nutritivo de silagens de capim elefante (Pennisetum purpureum, Shum) com feno de gliricídia (Gliricidia sepium(Jacq.) Walp). Revista Verde de Agroecologia e Desenvolvimento Sustentável, v.8, n.2, p.240-246, 2013.

PACIULLO, D.S.C.; GOMIDE, J.A.; QUEIROZ, D.S.; SILVA, E.A.M. Composição química e digestibilidade in vitro de lâminas foliares e colmos de gramíneas forrageiras, em função do nível de inserção no perfillho, da idade e da estação de crescimento. Revista brasileira de Zootecnia, v.30, n.3, p.964-974, 2001.

PADUA, F.T.; ALMEIDA, J.C.C.; SILVA, T.O.; ROCHA, N.S.; NEPOMUCENO, D.D. Produção de matéria seca e composição químicobromatológica do feno de três leguminosas forrageiras tropicais em dois sistemas de cultivo. Ciência Rural, v.36, n.4, p.1253-1257, 2006.

PINHO, R.M.A.; SANTOS, E.; BEZERRA, H.F.C.; OLIVEIRA, J.S.; CARVALHO, G.G.P.; CAMPOS, F.S.; PEREIRA, G.A.; CORREIA, R.M. Avaliação de fenos de capim-buffel colhido em diferentes alturas de corte.

Revista Brasileira de Saúde e Produção Animal [online], v.14, n.3, p.437-447, 2013.
SAMPAIO, C.B.; DETMANN, E.; LAZZARINI, I.; SOUZA, M.A.; PAULINO, M.F.; VALADARES FILHO, S.C. Rumen dynamics of neutral detergente fiber in cattle fed low-quality tropical forage and supplemented with nitrogenous compounds. Revista Brasileira de Zootecnia, v.38, n.3, p.560-569, 2009.

SANDERSON, M.A.; WEDIN, W.F. Nitrogen concentrations in cell wall and lignocellulose of smooth bromegrass herbage. Grass and Forage Science, v.44, n.2, p.151-158, 1989.

VAN SOEST, P.J. Nutritional ecology of the ruminant. 2.ed. Ithaca: Cornell University Press, 1994. 476p.

WANDERLEY, W.L.; FERREIRA, M.A.; BATISTA, A.M.V.; VÉRAS, A.S.C.; SANTOS, D.C.; URBANO, S.A.; BISPO, S.V. Silagens e fenos em associação à palma forrageira para vacas em lactação. Consumo, digestibilidade e desempenho. Revista Brasileira de Saúde e Produção animal [online], v.13, n.3, p.745-754, 2012.

ZANINE, A.M.; DINIZ, D. Qualidade, conservação, método de cura, relação folha:caule e consumo de feno de gramíneas tropicais. Revista Eletrônica de Veterinária, v.7, n.9, p.1-7, 2006.

Data de recebimento: 08/05/2015

Data de aprovação: 21/06/2016 